\title{
The Socialisation and Interaction in the Volunteer Experience
}

\author{
Qing-qing Lin $^{1} \&$ Julie Jie Wen ${ }^{2}$ \\ ${ }^{1}$ School of Tourism Management and South China Ecological Civilisation Research Centre, South China Normal \\ University, Guangzhou, China \\ ${ }^{2}$ School of Social Sciences, Western Sydney University, Sydney, Australia \\ Correspondence: Julie Jie Wen, School of Social Sciences, Western Sydney University, Penrith South D.C. 1797, \\ Australia.
}

Received: September 10, 2020

Accepted: October 19, 2020

Available online: October 22, 2020

doi:10.11114/ijsss.v8i6.5052

URL: https://doi.org/10.11114/ijsss.v8i6.5052

\begin{abstract}
Volunteering experience is believed to provide the potential for the socialisation and interaction of the participants. By means of observations, focus group and interviews, the research attempts to analyse the volunteering process and attitude shifts in relation to volunteering. Findings of the research confirm that apart from helping the destinations, volunteers develop their personalities and attitudes towards life during their journey of helping children in rural China. A wide range of interactions and socialisation opportunities take place before, during, and after volunteering. Volunteers benefit in the confirmation of self-value, interaction, learning and socialisation. The research concludes that volunteering makes notable contribution to youth development and poverty alleviation.
\end{abstract}

Keywords: China, interaction, rural; socialisation, volunteer, youth development

\section{Introduction}

There is growing volunteering activity throughout the world. Originally a British and European phenomenon, volunteering has evolved into a global movement (Wearing \& McGehee, 2013). Volunteering in the research is defined as "those tourists who, for various reasons, volunteer in an organised way to undertake holidays that might involve aiding or alleviating the material poverty of some groups in society, the restoration of certain environments, or research into aspects of society or environment" (Wearing, 2001:1).

Volunteering is labelled as part of the special interest tourism that focuses on experiential learning, education, destination development, and interaction (Wearing \& Neil, 2001). While volunteer can help poorer region by providing external expertise and network, research suggests that volunteering has positive impacts on the participants (Wearing, 2001; Gray \& Campbell, 2007). The involvement and interaction with the destination community in volunteering offers the potential to nurture a sense of responsibility and altruism, leading to desirable outcome in youth development.

Traditionally, volunteering involves youth from rich countries in Europe and North America to work in Asian, South America and African countries (Alexander, 2012). However, with growing gap between different regions in China, it has been promoted to send college students in affluent urban areas to volunteer in rural China.

This research undertakes analysis on college students from Jiangsu University, located in Zhenjiang, Jiangsu Province, China, volunteering in the Sunflower project. Sunflower is an organisation established in 2009 by students in Jiangsu University. It organises students to work as volunteers to raise the awareness of the public by riding bicycles to rural China to make publicity of the alarming situation in some disadvantaged areas. Students ride bicycles to rural villages in Jiangsu and Anhui Province, working there for one to three weeks teaching primary school children.

The paper starts from theoretical discussion on volunteering and the social development of the youth. Detailed analysis of socialisation and interaction during the volunteering experience is presented. The paper concludes with recommendations on improving the quality of volunteering.

\section{Theoretical Background}

There is a wide body of research on volunteers, including their motivation, and the impacts of volunteering after the experience (Callanan \& Thomas, 2005; Lepp, 2008; McIntosh \& Zahra, 2007). 


\subsection{In-depth Interaction}

Volunteering encourages understanding and interaction between volunteers and the locals over an extended length of time, providing incentives for the volunteers to explore the connections with not only the locals, but also among the volunteers (McGehee, 2002). Volunteering fosters a mutually beneficial and reciprocal interaction between the volunteer and the local villagers. The reciprocity encourages the youth to engage with the stakeholders in the volunteering process, while and the in-depth interaction may help the youth to re-negotiate their identity and social roles (McIntosh \& Zahra, 2007). The high frequent interaction with the peers and local community establishes an alliance and strong ties. Since volunteers often share food, conversation and riding sessions during excursions, they exchange information about life and work, resulting in emotional and professional connections that might continue for the rest of their life (McGehee, 2002).

Volunteering fosters intimate interaction with the local villagers, and even blends the social values between the youth and local community (Singh, 2002). Instead of quick and artificial interactions that often occur in other forms of travel, volunteering offers more authentic and intense interactions. Some scholar uses such description as non-superficial, engaging, lasting, fun, and mutually beneficial to describe this type interaction (McIntosh \& Zahra, 2007). Interactions and cultural exchange may lead to shifts such as local pride, destination development, landscape renewal, cultural hybridity, and youth development (Wen, Lin \& Peng, 2018).

\subsection{Socialisation}

Social network provides links of friends and associates who support each other in ideas and pursuits (McGehee \& Santos, 2005). Individuals exist in the groups instead of independent entities in isolation as they need to interact with others (Crompton, 1981). Socialisation presents a complex learning journey that participants come to terms with the values, attitudes and norms in the society (Lin \& Wen, 2018). Volunteers are more intricately linked with the community affairs in the destination, hence they have opportunity for socialisation (Sin, 2009).

Socialisation requires the establishment of social network and ties. Volunteering fosters socialistion and networking during three stages, which are pre-trip, during the trip and post-trip. Volunteers describe the experience as 'enlightening', 'ever-lasting' and 'life changing' (McGehee \& Santos, 2005). Volunteers understand their normal social life and networks differently after volunteering, and they feel like a new person, with more strength to jump out of the comfort zone (Desforges, 1998).

The networks and the consciousness-raising experience may improve the satisfaction of volunteers (McGehee \& Norman, 2002; McGehee \& Santos, 2005). Volunteering fosters positive effects on "openness, civic attitudes, and wisdom of the college participants" (Bailey \& Russell, 2010). Volunteers have access to activities that promote socialization and enlightenment (Matthews, 2008; Sin, 2009; Wearing, 2002). "The self of volunteers can be better identified when they encounter other volunteers, locals, and other members who did not have the volunteer experience" (Sin, 2009). In volunteering, travelling together encourages still development and "may perform a desired identity which will in turn secure entry to the privileges of work, housing and lifestyle" (Desforges, 1998:177).

When people work and live together "on jobs of social significance, they develop understanding and friendships that are more important to them than the physical construction" (Clark, 1978:13). Volunteering provides nutritious life experiences in the rich natural and cultural environment, filled with deep contact with the destination, negotiation of identity, novel networking and youth development. Indeed, socialisation co-exists with the volunteering experiences.

\subsection{Volunteering and Youth Development}

As part of the niche and alternative tourism, volunteering offers direct interaction with the destination over an extended period of time (Singh, 2004). Some participants travel around in small teams, and there are intense interactions among the group members. Volunteering may initiate value shifts and changed consciousness, influencing both the volunteer and the local community in the process of interactions (Stoddart \& Rogerson, 2004). Researchers believe there exists "intrinsic growth and satisfaction among hosts and guests through interactions in volunteering" (Uriely, Reichel \& Ron, 2003).

Wearing (2001) identified four main categories of personal development in volunteering, including "personal awareness and learning, interpersonal awareness and learning, confidence and self-contentment". All these outcomes are essential in fostering positive worldview for the youth.

Recreation activities within the group cover social components, and construct meanings for the youth via interaction and share activities (Wearing, 2001). When volunteers interact with their colleagues, the dynamic diverts from what occurs with the villagers. "Individual and group interaction will impact upon the volunteer's sense of self and identity" (Wearing, 2001). Interactionism may explain characteristics across various cultural settings, and assist with cross-cultural awareness and appreciation (Wen, Lin \& Peng, 2018). 


\section{Research Method}

\subsection{Research Design}

Researchers applied the observation methods when working with the correspondent at Taicang, Jiangsu Province, in order to collect data on site. Photos were taken with permission. During five days with the volunteers, researchers collected data from focus group discussions, in-depth interviews and personal observation. Further interviews were conducted after volunteers returned to Jiangsu University in late October 2019. Thematic analysis was used in the analysis of data.

\subsection{Populations and Sampling}

Convenience sampling method was applied for the recruitment of interview and focus group. Around 31 volunteers were involved in the focus groups and interviews. The researchers joined Sunflower in early October 2019 to experience the volunteering process.

\section{Research Findings and Discussions}

Volunteering serves as the eye opening opportunity to help the youth in recognising their value from the trust and appreciation of the villagers. Volunteers learn from the experience, and benefit from the interaction and socialisation from the whole process.

\subsection{Value Recognised}

Values relate to "perception, understanding, judgement and choice of a person based on the perception" (Chen \& Chen, 2011). The volunteers are full time students, and very few of them have worked before. Since the local students and parents deeply appreciate what the volunteers do, and the local principals and teaching staff promote the new technology and teaching methods offered by Sunflower project, volunteers feel proud of what they can really deliver, and become more confident of their capability.

The impacts associated with the volunteering program is apparent. Villagers practice their mandarin with volunteers and bring home cooked food. Parents of the local students appreciate the dedication of the young volunteering teachers so much that they often expand the family budget on their children's schooling requirement. Village children have more dreams about studying hard and attending universities in a big city. One volunteer comments with tears in her eyes:

Never did I know that I could change people's life until today. My students promised me they will visit me in Zhenjiang, and will get into universities. I have more knowledge and experience about the education in rural China, and I found my compassion and value for life.

Confidence delivers the faith one person carries with completing a challenging assignment. There appears to be a general consent that volunteering improves the sense of competency and self-contentment from the research.

Volunteering helps the youth to learn what they can and what they cannot achieve, and come to terms with the consciousness of limits. The focus group confirms that the volunteers enjoy sharing their experience on how to accept the limits and move on during the activity. They form a clearer idea that both volunteer activity and individual personal development are important. They also realise that it is not detrimental if volunteers cannot give a new life to the poor village. It takes long and consorted work to improve the world, and as long as they make some contribution, they should be proud of themselves.

\subsection{Learning in Volunteering}

Cooperation is important when interact with different stakeholders, including new recruitment, veteran participant, program manager, village teacher, local principal, local students and their family, and the village residents.

Sunflower provides the platform for volunteers to learn new skills through training course before the riding starts. Knowledge sharing sessions are organised between seniors and new volunteers of the program. Communication is constant between village teachers in the local school and volunteering teachers. One respondent makes this comment:

We learn from each other to improve our work. For example, members have learning sessions in the evening to compare different ways to work with the village students and how to make them more interested in learning. The local principal gives us tips on how to control students. I also learn the local dialect and wear the local clothes to get closer to the villagers.

\subsection{Interactions during Volunteering}

There is complex interaction within and outside the volunteering group. Sunflower expands quickly and new volunteer members constantly recruited by the program. The relationship of team members is complicated as a result of the quick expansion and diversification across teams. Small groups within one group exist, allowing some members to interact more intensely.

There are two-way interactions between and among the stakeholders. There are also frequent interactions between 
volunteers and the school principal, since the principal supports the volunteer activities and appreciates Sunflower. Interactions with diverse stakeholders helps in supporting close relationship and obtaining improved communication skills, with enrichment in the interpersonal conceptions. During the focus group discussions, respondents agree that rich interaction context during volunteering prepares the youth to become better communicators and calmer actors in life.

\subsection{The Socialisation of the Volunteers}

The youth are in search of identity and meaning of life. Volunteers live and work with other people during challenging time, and this experience contributes to the socialisation of the young people, including personal consciousness, learning, interpersonal relationship, confidence, self-value and sense of achievement. Volunteers are taken out of the routines to act in a new role set to deal with unfamiliar social situations. They are granted the mission to explore their new roles for self-development and individual identity.

Volunteering presents the challenge to understand the reality in the disadvantaged regions of China, where young children are often separated from parents for months when the adults have to work in big cities like Shanghai and Nanjing to earn an income. Grand-parents do not have a good education background, hence there is little support from the family for the primary education. Volunteers move out of their 'ivory tower' to face the society, as one male respondent comments:

I thought I was tough guy ready to deal with life. However, when the poor family here is struggling to make the ends meet, I complain about the amount of financial help my parents provide. I feel so guilty. I realised that I was a weak parasite who lived on the kindness of my parents. I have to change and grow up now.

\section{Conclusion}

Volunteers have the potential to make contribution to poverty alleviation, professional development and identity confirmation. They are offered life changing experience during young adult life, leading to the achievement personal growth and new social circles. They learn to prepare for the reality and build a meaningful future. The young people learn to negotiate with stakeholders and deal with conflict. They experience eye opening events and become better prepared for a brighter future.

Volunteering is normally a voluntary option and only a small number of college students take this task during their vacations. Since it is proven to be such a rewarding experience, the research recommends adoption of volunteering arrangement in the mainstream of tertiary syllabus. It is needed for the public policy to support this type of youth development program, providing legal framework and financial incentives to encourage the activity.

There is also concern that volunteers work for a few weeks and then leave, and there is no guarantee of the consistency of arrangement. It is suggested that educational bodies work more with different levels of governance, encouraging a sustainable dialogue among stakeholders, to connect the local school with long term volunteering program.

The research is not able to contact the village residents or primary school children due to the requirement of ethics and resources. Future work on the reflection of the local community would strengthen the validity of the research.

\section{Acknowledgement}

This work was supported by National Natural Science Foundation of China (No: 41801127 ' No:71874164 No:41701144 - No:41801128), and Major Program of National Social Science Foundation of China (18ZDA161).

\section{References}

Alexander, Z. (2012). International volunteer tourism experience in South Africa: an investigation into the impact on the tourist. Journal of Hospitality Marketing and Management, 21(7), 779-799. https://doi.org/10.1080/19368623.2012.637287

Bailey, A., \& Russell, K. (2010). Predictors of interpersonal growth in volunteer tourism: a latent curve approach. Leisure Sciences, 32(4), 352-368. https://doi.org/10.1080/01490400.2010.488598

Callanan, M., \& Thomas, S. (2005). Volunteer tourism: deconstructing volunteer activities within a dynamic environment. In M. Novelli (Ed.), Niche Tourism: Contemporary Issues, trends and cases (pp.183-200). Oxford: Butterworth-Heinemann. https://doi.org/10.1016/B978-0-7506-6133-1.50025-1

Chen, L. J., \& Chen, J. S. (2011). The motivations and expectations of international volunteer tourists: a case study of "Chinese Village Traditions". Tourism Management, 32(2), 435-442. https://doi.org/10.1016/j.tourman.2010.01.009

Clark, K. (1978). The Two-way Street-a Survey of Volunteer Service Abroad. Wellington: New Zealand Council for Educational Research.

Crompton, J. L. (1981). Dimensions of the social group role in pleasure vacations. Annals of Tourism Research, 8(4), 
550-568. https://doi.org/10.1016/0160-7383(81)90041-4

Desforges, L. (1998). "Checking out the planet”: global representations/local identities in youth travel. In T. Skelton and G. Valentine (Eds.), Cool Places: Geographies of Youth Cultures (pp.175-192). London: Routledge.

Gray, N. J., \& Campbell, L. M. (2007). A Decommodified experience? exploring aesthetic, economic andethical values for volunteer ecotourism in Costa Rica. Journal of Sustainable Tourism, 15(5), 463-482. https://doi.org/10.2167/jost725.0

Lepp, A. (2008). Discovering self and discovering others through the Taita Discovery Centre Volunteer Tourism Programme, Kenya. In K. Lyons, \& S. Wearing (Eds.), Journeys of discovery in volunteer tourism: international case study perspectives (pp. 86-100). Wallingford, UK: CABI.

Lin, Q. Q., \& Wen, J. (2018). Tea tourism and its impacts on ethnic marriage and labor division. Journal of China Tourism Research, 14(4), 461-483. https://doi.org/10.1080/19388160.2018.1511490

Matthews, A. (2008). Negotiated selves: exploring the impact of local-global interactions on young volunteer travellers. In K. Lyons, and S. Wearing (eds.), Journeys of discovery in volunteer tourism:international case study perspectives (pp. 101-117). Wallingford, UK: CABI.

McGehee, N. (2002). Alternative tourism and social movements. Annals of Tourism Research, 29(1), 124-143. https://doi.org/10.1016/S0160-7383(01)00027-5

McGehee, N. G., \& Norman, W. (2002). Alternative tourism as impetus for consciousness-raising. Tourism Analysis, 6(3-4), 239-251.

McGehee, N., \& Santos, C. (2005). Social change, discourse, and volunteer tourism. Annals of Tourism Research, 32(3), 760-779. https://doi.org/10.1016/j.annals.2004.12.002

McIntosh, A. J., \& Zahra, A. (2007). A cultural encounter through volunteer tourism: towards the ideals of sustainable tourism. Journal of Sustainable Tourism, 15(5), 541-556. https://doi.org/10.2167/jost701.0

Sin, H. L. (2009). Volunteer tourism: "involve me and I will learn". Annals of Tourism Research, 36(3), 480-501. https://doi.org/10.1016/j.annals.2009.03.001

Singh, T. V. (2002). Altruistic tourism: another shade of sustainable tourism: the case of Kanda community. Tourism (Zagreb), 50(4), 361-370.

Stoddart, H., \& Rogerson, C. M. (2004). Volunteer tourism: the case of Habitat for Humanity South Africa. GeoJournal, 60(3), 311-318. https://doi.org/10.1023/B:GEJO.0000034737.81266.a1

Uriely, N., Reichel, A., \& Ron, A. (2003). Volunteering in tourism: additional thinking. Tourism Recreation Research, 28(3), 57-62. https://doi.org/10.1080/02508281.2003.11081417

Wearing, S. (2001). Volunteer tourism: experiences that make a difference. London: CABI. https://doi.org/10.1079/9780851995335.0000

Wearing, S., \& McGehee, N. G. (2013). Volunteer tourism: a review. Tourism Management, 38(1), 120-130. https://doi.org/10.1016/j.tourman.2013.03.002

Wearing, S., \& Neil, J. (1997). Tourism that counts: ecotourism, volunteerism and serious leisure. In Tourism research, Building a better industry (pp. 141-154). Canberra: Bureau of Tourism Research.

Wearing, S., \& Neil, J. (2001). Expanding sustainable tourism's conceptualization: ecotourism, volunteerism and serious leisure. In S.F. McCool and R.N. Moisey (eds.) Tourism, recreation and sustainability, linking culture and the environment (pp.233-255). New York: CABI Publishing. https://doi.org/10.1079/9780851995052.0233

Wen, J., Lin, Q., \& Peng, B. (2018). The interpersonal interaction and socialisation of volunteers: Case Study of Ride for Love. In khoo-lattimore, C. and Yang, E. (eds.) Asian youth travellers insights and implications (pp. 175-185). Germany: Springer.

Zahra, A., \& McGehee, N. G. (2013). Volunteer tourism: a host community capital perspective. Annals of Tourism Research, 42, 22-45. https://doi.org/10.1016/j.annals.2013.01.008

\section{Copyrights}

Copyright for this article is retained by the author(s), with first publication rights granted to the journal.

This is an open-access article distributed under the terms and conditions of the Creative Commons Attribution license which permits unrestricted use, distribution, and reproduction in any medium, provided the original work is properly cited. 